\title{
Rafael Myro*
}

\section{LA INDUSTRIA ESPAÑOLA DESPUÉS DE LA PANDEMIA}

En este artículo se analiza, en primer lugar, el impacto de la pandemia sobre la industria manufacturera española, que le ha hecho perder posiciones en el espacio comunitario; a continuación, se identifican las exigencias del proceso de reindustrialización que España ha de afrontar sin dilación. Finalmente, se definen los objetivos e instrumentos de la política industrial que hoy se necesita. Las ayudas que España va a recibir del fondo de recuperación europeo deberían facilitar la consecución de objetivos ambiciosos, así como un profundo giro en las concepciones hoy prevalecientes acerca del papel de la intervención pública en la industria y de las formas más eficaces de llevarla a cabo.

\section{Spanish industry after the pandemic}

This article examines, first of all, the impact of the pandemic on Spanish manufacturing industry, which have resulted in it losing ground within the EU; then the demands of the re-industrialization process that Spain has to face without delay are analysed. Finally, the objectives and instruments of industrial policy which are needed today are defined. The aid that Spain will receive from the European recovery fund should facilitate the achievement of ambitious industrial objectives, as well as a profound transformation of the prevailing attitude toward the extent public intervention and its most effective implementation.

Palabras clave: manufacturas, desarrollo industrial, politica industrial, crecimiento económico. Keywords: manufacturing industry, industrial development, industrial policy, economic growth. JEL: L52, O10, O14, O24, O25.

1. Introducción

En el momento de escribir estas páginas, a finales de marzo de 2021, la economía europea vive un tercer rebrote de la pandemia originada por el SARSCoV-2 que no resulta fácil de controlar sin recurrir a

\footnotetext{
* Universidad Complutense de Madrid.

Contacto: rmyrosan@ucm.es

Versión de marzo de 2021.

https://doi.org/10.32796/ice.2021.919.7172
}

nuevas medidas de confinamiento. En el transcurso del año que se acaba de cerrar, esta enfermedad ha afectado de forma intensa a la economía española, que apenas se había recuperado de los efectos de la Gran Recesión iniciada en 2008. El producto interior bruto (PIB) se redujo en 2020 un 10,8 \% con respecto al año anterior, una cifra sensiblemente superior a la media de la eurozona (en la que la reducción no superó el 7 \%). Ni el Banco de España, ni la Comisión Europea esperan que este agregado económico recupere el volumen alcanzado en 2019 antes del comienzo de 
2023. Sobre esta base, el crecimiento medio del PIB español que se registraría entre 2008 y 2022 sería tan solo de un $0,4 \%$ anual.

Esta disminución del PIB ha sido principalmente la consecuencia de las intensas medidas de restricción de la actividad productiva y de confinamiento de la población que se adoptaron desde el 14 de marzo al 21 de junio de 2020, periodo en el que se impuso un primer estado de alarma. Antes del final de este, la economía inició una recuperación que los nuevos brotes del virus han ralentizado.

Los sectores industriales no fueron los principales destinatarios de las medidas de confinamiento pero, aun así, han debido enfrentarse a los efectos indirectos del cierre de muchas actividades de servicios, así como a los de reducción de la demanda de consumo, exportaciones y bienes de equipo. Se han enfrentado pues a un shock de demanda similar al que sufrieron con ocasión de la Gran Recesión, cuando aún no habían conseguido restablecer los niveles de producción anteriores a esta.

La recuperación industrial, que se inició con fuerza en el tercer trimestre del año 2020, para moderarse ligeramente después, debe marcar el inicio de un nuevo periodo, no solo de reconstrucción de los daños causados por la pandemia, sino también de acelerada transformación industrial, en estrecha conexión con la ambiciosa agenda industrial europea, que, liderada por Alemania, busca convertir la inesperada recesión en una oportunidad para afrontar con decisión los retos pendientes; dos ante todo, el de la digitalización, con la mira puesta en el desarrollo de la Inteligencia Artificial y la economía de los datos, y el de la transición energética, que afecta profundamente a la industria automovilística, de gran importancia para toda Europa.

Con el fin de profundizar en los desafíos pendientes y ofrecer algunas orientaciones para la política industrial, en las páginas que siguen, se estudian, en primer lugar, los efectos de la pandemia sobre la industria manufacturera; a continuación, las exigencias del proceso de reindustrialización de España. Finalmente, se definen los objetivos de la política industrial que hoy se necesita, y se discuten algunos aspectos del marco institucional que debería presidir su desarrollo.

\section{El impacto de la pandemia sobre la producción manufacturera}

Con los datos provisionales de la Contabilidad Nacional Trimestral de España, el Valor Añadido Bruto (VAB) de las manufacturas se redujo ya en el primer trimestre del año 2020 un 6,2 \%, con respecto al mismo trimestre del año anterior, más que en el conjunto de la economía, y más de lo esperado según algunas estimaciones disponibles ${ }^{1}$. La razón de ello se encuentra en el elevado impacto provocado por la disminución de las exportaciones de bienes, que en marzo se desplomaron un $14,5 \%$, y por el descenso de la demanda de bienes de consumo duradero (de un $15,5 \%$ ), y de maquinaria, bienes de equipo y sistemas de armamento (7,8\%). Recuérdese que, tras la intensa orientación de las empresas industriales hacia los mercados exteriores en las últimas décadas, en 2019 se exportaba algo más de un $40 \%$ de la producción manufacturera, de forma que la demanda externa influye mucho en la actividad industrial.

El segundo trimestre del año fue aún más recesivo, con una disminución del VAB manufacturero de nuevo superior a la del conjunto de la economía, nada menos que de un $27,8 \%$ en términos anuales. Las exportaciones de bienes se hundieron en ese periodo un $27 \%$, la demanda de bienes de consumo duradero un $37,3 \%$,

\footnotetext{
Según las ofrecidas por Prades y Tello (2020), que recogen el efecto del confinamiento, cada semana de cierre moderado durante el periodo de vigencia del estado de alarma, habría dado lugar a una reducción del VAB total de la economía española del $17 \%$, directamente, y del $28 \%$, cuando se incluye el efecto de arrastre sobre otras actividades. EI VAB de la industria manufacturera habría disminuido directamente en un $11,1 \%$, por el efecto exclusivo de las ramas de equipos de transporte y equipos eléctricos, y en un $24,2 \%$, como consecuencia del efecto de arrastre de las restantes ramas de la economía. Esta cifra aplicada a solo 16 días del mes de marzo daría lugar a una reducción del VAB manufacturero durante el primer trimestre de 2020 de tan solo un $2,8 \%$.
} 
la de inversión en maquinaria, bienes de equipo y armamento, un $33,2 \%$ y la inversión en material de transporte, un $53,5 \%$.

El mes de abril, con un cierre total de actividades no esenciales durante sus primeros nueve días, anotó los máximos recesivos, como bien refleja el Índice de Producción Industrial. Los bienes más afectados fueron los de consumo duradero y los de equipo. Descendiendo a un mayor nivel de detalle, los más afectados fueron aquellos sectores que reciben efectos de arrastre más elevados de los restantes, y son más sensibles a las actividades presenciales de la población. En primer lugar, la industria principal del automóvil, cuya producción registró una reducción interanual del 98,7\%, la de componentes, piezas y accesorios del $88 \%$ y la de carrocerías y remolques del $62,5 \%$. Los muebles, los artículos de joyería y los juegos y juguetes anotaron caídas de sus producciones superiores al $70 \%$, al igual que el calzado y la confección de prendas de vestir, seguidos muy de cerca por los acabados textiles; la actividad de las industrias de metales se contrajo cerca de un $50 \%$, algo más que la de materiales de construcción, acercándose la cifra correspondiente al $40 \%$ en las de maquinaria. En las industrias químicas o en las de alimentos, el descenso de la producción no fue tan elevado, salvo en fibras artificiales y plásticos, entre las primeras, o productos de panadería, pastas alimenticias y bebidas, entre las segundas, donde la producción se redujo en más de un $20 \%$.

La evolución de las exportaciones siguió pautas similares a las de la demanda interna, afectando más a los bienes de consumo duradero y a los bienes de equipo, en particular automóviles y componentes, confección, energía y aeronaves.

Pero ya en el tercer trimestre del año, la tónica recesiva se moderó sustancialmente, con una reducción del VAB de las manufacturas con respecto al año anterior de solo un $5,4 \%$, que reflejaba una apreciable remontada de la actividad, fruto de una normalización de las demandas anteriormente mencionadas: con respecto al mismo trimestre del año anterior, la exportación de bienes se redujo tan solo un 5,1\%, la de bienes de consumo duradero aumentó un $0,8 \%$ y la de maquinaria, bienes de equipo y armamento disminuyó un 6,9\%. El Índice de Producción Industrial del tercer trimestre refleja la normalización de la producción de bienes de consumo duradero. Sorprende la intensa recuperación del automóvil y sus componentes, el textil y la confección, los productos de caucho y los productos metálicos. El cuarto trimestre mantuvo la tónica de mejora, con un nivel de actividad en torno al $96 \%$ del alcanzado en 2019.

Fruto de esta dinámica de mejora a partir del tercer trimestre, el año 2020 finalizó con una reducción del VAB manufacturero de un $10,7 \%$ con respecto al año anterior, muy similar a la del PIB, del 10,8 \%. Para el año 2021 podría esperarse un crecimiento del producto industrial de alrededor del $8 \%$, si efectivamente se consigue mantener bajo control el tercer brote del virus iniciado en diciembre de $2020^{2}$.

Aun con estas favorables perspectivas, en 2022, el VAB de las manufacturas en España seguiría lejos del que tenía antes de la Gran Recesión, y también lo estaría el volumen de empleo generado (Figura 1). A diferencia del PIB español, que recuperó la cifra alcanzada en 2008 nueve años después, a comienzos de 2017, la industria manufacturera no había conseguido volver al VAB de entonces aún en 2019. Aún se encontraba más lejos en sus niveles de empleo, que en 2020 se han reducido aún más. En el cuarto trimestre de este último año, aún con incertidumbre con respecto al destino final de los trabajadores en ERTE (Expediente de Regulación Temporal de Empleo), las manufacturas españolas dieron empleo a un conjunto de trabajadores un $23,4 \%$ menor que en el mismo trimestre de $2008,574.900$ trabajadores menos. Las horas trabajadas también fueron inferiores en un 24,9\%.

Además, aunque el peso de la industria en el PIB ascenderá posiblemente de forma muy ligera en 2020 y lo hará más en 2021, continuando la senda

2 El FMI pronostica en su último World Economic Outlook, de enero de 2021, un aumento del 5,9 \% del PIB para España. 


\section{FIGURA 1}

\section{EVOLUCIÓN DEL VAB REAL DE LAS MANUFACTURAS \\ (Números índices, base 100 en 2015)}

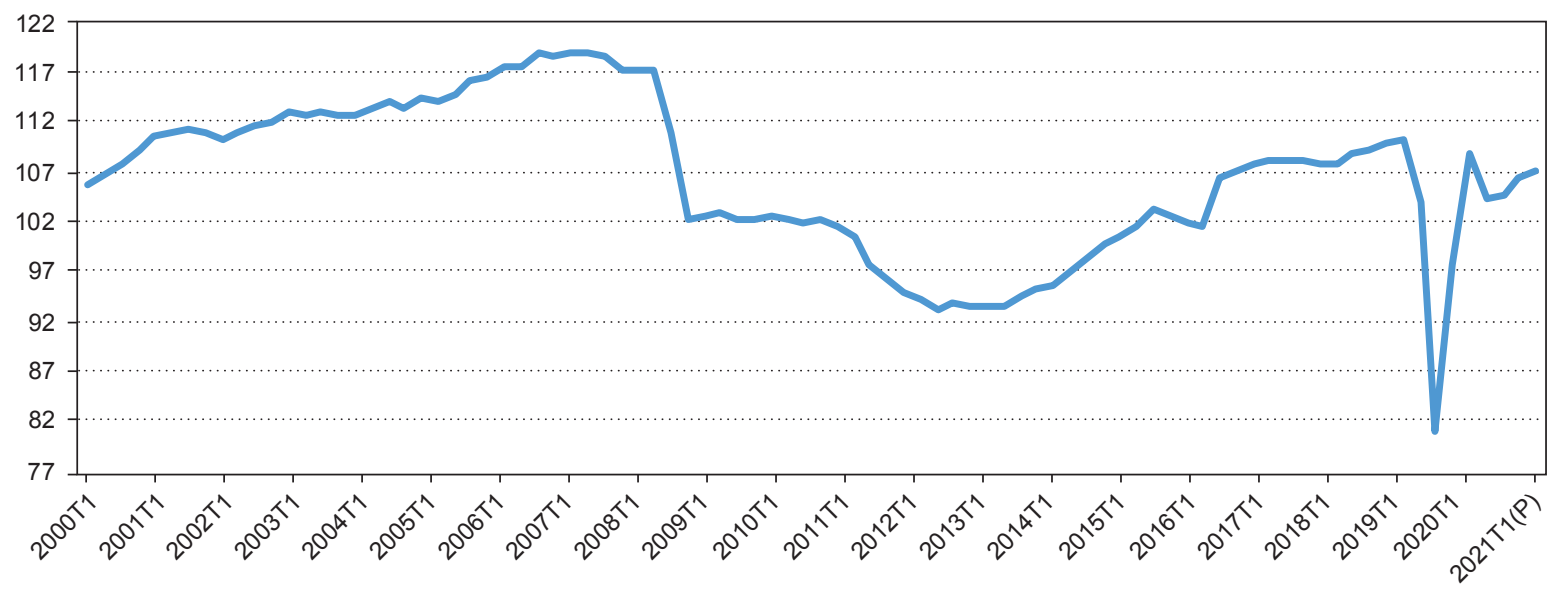

NOTA: $(P)=$ Previsión.

FUENTE: INE, Contabilidad Nacional Trimestral y elaboración propia.

seguida durante el periodo de recuperación tras la Gran Recesión, se mantendrá lejos de la añorada cifra del $20 \%$, cuyo alcance exigiría revertir la tendencia desindustrializadora de las últimas décadas.

Por otra parte, la importancia de España en la industria europea seguirá reduciéndose (Figura 2), como ya sucedió durante la Gran Recesión, poniéndose cada vez más en riesgo la cuarta posición que ocupa después de la marcha del Reino Unido, ya amenazada por Irlanda y por Polonia, dos países que han conseguido un rápido desarrollo de sus industrias en el siglo actual, e incluso por los Países Bajos.

A la vista de la situación descrita, no cabe minusvalorar el gran reto al que la industria española se enfrenta. No solo tiene pendiente recuperar lo perdido en las dos recesiones recientes, sino también aumentar de forma significativa su peso en el PIB, en un contexto de profundos cambios tecnológicos y productivos, los derivados de las transiciones ecológica y digital, que la pandemia va a acelerar.
Sin embargo, contará para afrontar ese reto con un nuevo marco europeo muy favorable, de apuesta firme por la reindustrialización, que lideran Alemania y Francia, países que reclaman una mayor autonomía tecnológica y productiva de la UE con respecto a EE UU y China, y un espacio productivo mayor para la industria y los servicios avanzados, objetivos a los que dedicarán abundantes recursos. También contará con la financiación del Fondo de Recuperación Europeo Next Generation EU.

En estas condiciones, España se encuentra pues ante un gran reto, pero también ante una gran oportunidad que el Gobierno nacional y los Gobiernos regionales deben aprovechar, implementando una nueva política industrial, más ambiciosa, que, reclamada ya desde hace varios años, y exigida con mayor claridad tras la Gran Recesión, se convierte ahora en urgente e ineludible.

Sin excluir otros posibles objetivos, España debe aprovechar esta oportunidad para afianzar su ya elevada inserción en la fábrica industrial europea, conseguida no sin gran esfuerzo, y que tan buenos réditos 


\section{FIGURA 2}

\section{LA INDUSTRIA MANUFACTURERA EN EUROPA}

(VAB en miles de millones de euros de 2015)

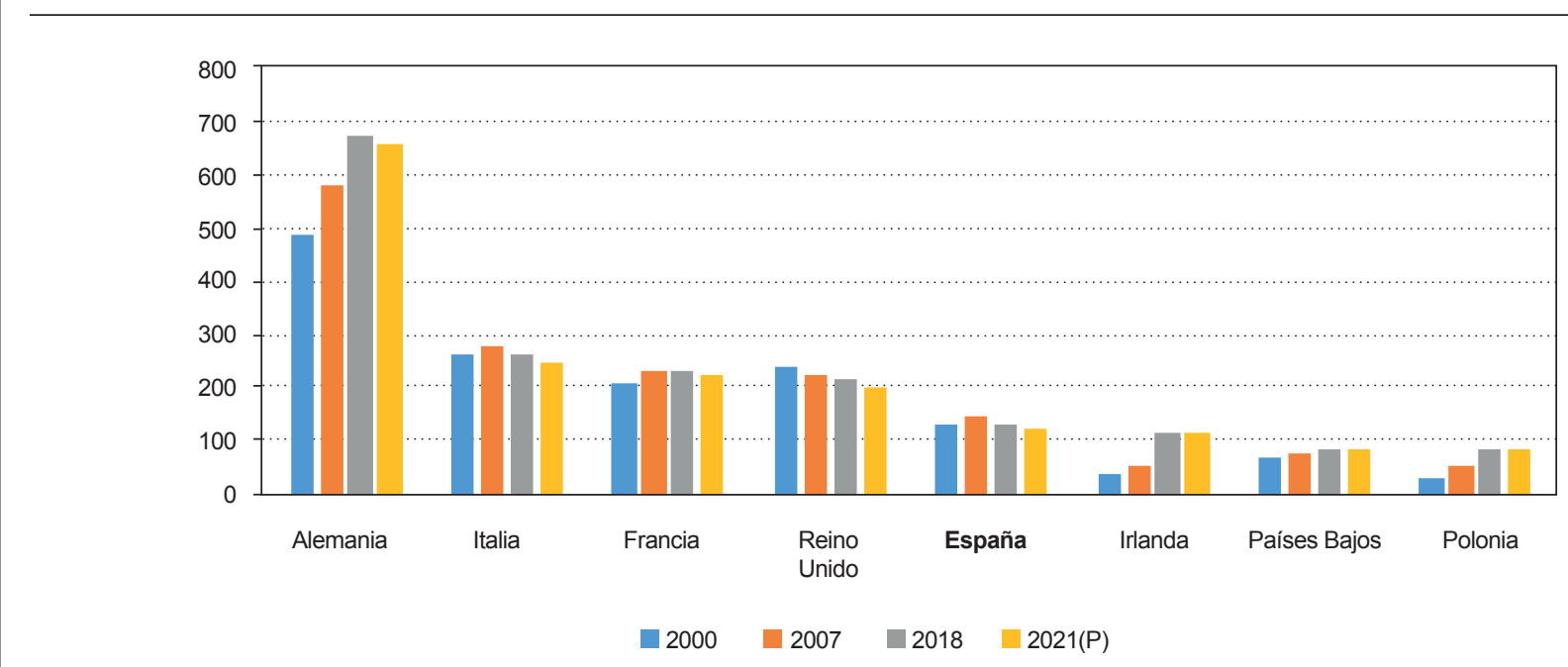

NOTA: $(\mathrm{P})=$ Previsión.

FUENTE: Eurostat.

le ha dado. Lo logrado en el sector del automóvil ilustra bien el camino a seguir. En su producción, nuestro país ocupa el segundo lugar en Europa, después de Alemania. Es uno de los sectores clave en la exportación española, que ahora afianza sus redes productivas en Marruecos, en donde la empresa SEAT ha pasado, de ser importador de inputs para ensamblar el producto final en nuestro país, a ser exportadora de inputs para ensamblar allí el producto final, de acuerdo con la mayor ventaja de costes de ese país en esa fase final (Moreno \& Fernández de Bobadilla, 2019). El comercio de inputs intermedios en este sector con Alemania e Italia, en particular, pero también con Francia (además del Reino Unido) es muy intenso (Tabla 1).

También es intenso este comercio en otros dos sectores de gran relieve en las exportaciones e importaciones de España, química y alimentos, con Alemania destacando en ambos casos como principal socio comercial (Gandoy et al., 2016). Este comercio tiene lugar en un porcentaje elevado entre casas matrices y filiales de las empresas multinacionales.

La inserción de España en la cadena de valor europea se ha producido también a través de las exportaciones de servicios intermedios, fundamentalmente de los denominados servicios avanzados, en concreto los servicios a empresas y los de telecomunicación e información. En estos servicios, en los que también sobresalen los lazos con Francia, Alemania y el Reino Unido, España ocupa la posición 11 entre los proveedores mundiales. Son servicios esenciales para la producción manufacturera pues contribuyen al avance de su productividad (Blázquez et al., 2017) ${ }^{3}$. Es pues claro que el desarrollo de las manufacturas no debe dejar de lado el de estos servicios; muy al contrario, estos han de formar parte de toda estrategia industrial.

3 El comercio exterior de los servicios no turísticos ha transformado la balanza de pagos de España, pues el saldo favorable obtenido en ellos representa hoy el $2 \%$ del PIB nacional, cuando al final de la década de 1990 registraba valores ligeramente negativos. 
TABLA 1

VAB EXTERIOR INCORPORADO EN LAS EXPORTACIONES DE AUTOMÓVILES DE CADA PAÍS (En \%)

\begin{tabular}{|c|c|c|c|c|c|}
\hline & España & Alemania & Francia & Italia & Reino Unido \\
\hline UE-14 ……………… & 26,0 & 13,2 & 13,3 & 14,3 & 19,0 \\
\hline 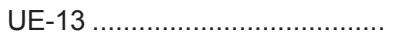 & 3,0 & 4,3 & 2,1 & 4,6 & 4,7 \\
\hline Total UE & 29,0 & 17,5 & 15,4 & 18,9 & 23,7 \\
\hline EE UU & 2,1 & 2,3 & 4,7 & 1,7 & 3,7 \\
\hline 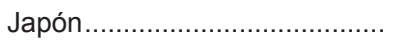 & 1,6 & 1,2 & 0,7 & 0,8 & 2,2 \\
\hline China & 2,1 & 1,6 & 1,2 & 2,0 & 2,9 \\
\hline 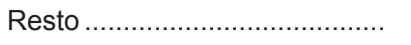 & 11,2 & 8,8 & 10,3 & 10,5 & 11,9 \\
\hline Total & 46,1 & 31,4 & 32,3 & 33,9 & 44,4 \\
\hline
\end{tabular}

\section{La transformación de la industria española}

La inserción en la gran fábrica europea no ha impedido a España consolidar posiciones propias en determinados sectores, ni extender sus exportaciones y empresas a otros territorios, como EE UU o Latinoamérica. En algunos casos, como en el de la industria de componentes de automoción, promoviendo la expansión internacional de la cadena de valor de los productos fabricados. Y si no se ha alcanzado un mayor nivel de autonomía tecnológica y productiva ha sido en parte debido a la falta de una política industrial de alcance. Será pues ahora imprescindible implementarla, si realmente se quiere dotar de ambición al objetivo de reindustrialización.

Por otra parte, no cabe albergar dudas acerca de los importantes réditos que se derivan de un firme apoyo a los sectores industriales. Por encima de otros posibles y más discutibles beneficios que a menudo se citan, como la introducción de nuevos modelos de gestión, o una cualificación de la mano de obra superior, destaca su gran importancia en la exportación (en España, las manufacturas suponen el $60 \%$ de ellas), que podría tender a perder relieve en los próximos años, debido a la rápida internacionalización de los servicios, los digitales principalmente.

Pero sobre todo, destaca el hecho de que ejecutan un elevado porcentaje del gasto empresarial en innovación. En 2018, de las 100 primeras empresas del mundo, ordenadas según su esfuerzo tecnológico, 83 eran manufactureras, y su gasto representaba el $42 \%$ del total, de forma que puede muy bien decirse que no hay esfuerzo innovador donde no hay manufacturas (Rodrik, 2004; Chang et al., 2013; Myro, 2018). Un resultado de su sobresaliente faceta innovadora es un crecimiento más destacado de la Productividad Total de los Factores, sobre todo en el subsector de maquinaria electrónica. Esto es compatible con el hecho de que muchos servicios avanzados, que son sobre todo de carácter intermedio, hayan crecido con mucha rapidez y absorbido grandes cantidades de mano de obra, contando con una elevada proporción de titulados STEM ${ }^{4}$ (Delgado \& Mills, 2018).

\footnotetext{
4 La palabra STEM es un acrónimo que tiene su origen en las siglas en inglés de Science, Technology, Engineering y Mathematics.
} 
Pues bien, la transformación que requieren las manufacturas españolas, la que debería permitirles, no solo recuperar el terreno perdido, sino aumentar su peso en el PIB, exige afrontar con éxito cuatro grandes retos: i) superar la pandemia; ii) ampliar y diversificar el tejido productivo, sofisticándolo tecnológicamente, al tiempo que haciéndolo más verde y digital, además de aumentando la presencia de multinacionales extranjeras; iii) diversificar los mercados de exportación; y iv) incrementar la productividad de las empresas.

En efecto, en primer lugar, en el corto y medio plazo, deben minimizarse los costes de la pandemia en términos de desaparición de empresas, cuidando sobre todo de aquellas más productivas y emblemáticas. Hasta que la pandemia esté controlada completamente, una vez alcanzada la inmunidad de rebaño a través de la vacuna, algo que probablemente no ocurrirá hasta el otoño de 2021, esto significa asegurarles las ayudas necesarias, incluso incrementando la deuda pública más allá de lo deseable. Además, será imprescindible facilitar los procesos de reestructuración e integración de empresas y arbitrar políticas activas de empleo para evitar la destrucción de capital humano.

En segundo lugar, en una perspectiva de medio y largo plazo, es necesario diversificar el tejido productivo, afianzando una senda en la que España ha destacado desde comienzos de siglo en el marco europeo, junto con Portugal (Álvarez-López \& Vega Crespo, 2020). En efecto, en comparación con sus socios europeos más desarrollados, tanto España como Portugal despuntan por haber anotado un mayor incremento en el número de mercancías que exportan con ventaja comparativa ${ }^{5}$. Fruto de ello, España aparece actualmente entre los países con un patrón de especialización más diversificado, solo por detrás de Italia, Alemania y Francia (Donoso \& Martín, 2017).

La industria de mayor éxito ha sido la farmacéutica, que ha doblado su peso en la oferta exterior y también

\footnotetext{
5 En 2016, el 70,65 \% de las exportaciones españolas procedía de
} productos con ventaja comparativa revelada. ha incrementado sus exportaciones a un ritmo más rápido que el alcanzado por los flujos mundiales de comercio. Asimismo, las industrias de otro material de transporte, alimentos, bebidas y tabaco, textil y confección, extractivas y otros productos manufacturados, han incrementado de forma apreciable su presencia en el patrón español, mejorando al mismo tiempo su cuota en el mercado global. Con una evolución menos destacada, las de maquinaria eléctrica, productos químicos y metálicas básicas han conseguido también elevar su peso en el patrón exportador español.

España posee pues fortalezas competitivas innegables en todos los sectores mencionados que deben seguir extendiéndose y afirmándose en los próximos años, incorporando las exigencias de la transición energética. Pero también debe aumentar su tejido productivo en las actividades de alta tecnología, donde posee una penetración muy baja, que además ha tendido a reducirse, con la excepción del segmento ya mencionado de farmacia y medicamentos. Entre otras, deberían recibir impulso las producciones de determinados instrumentos científicos y ópticos, así como las de equipos médicos, donde apenas se cuentan logros, pero existen claras posibilidades. Estas últimas actividades, junto a las de material sanitario, se han convertido en estratégicas con la pandemia, por más que su suministro resulte en gran medida garantizado por otros países de la UE (Paniagua, 2020). La COVID-19 conducirá a la búsqueda de un mejor equilibrio entre el logro de la máxima eficiencia en la producción y la consecución de una mayor resiliencia, lo que muy probablemente significará que aumentará el número de actividades industriales que los países decidan desarrollar internamente.

Por otra parte, debe incrementarse el grado de sofisticación de las producciones obtenidas, para enfrentarse con mayor competitividad a los nuevos países industrializados. Los logros en este aspecto han sido muy escasos, como indica la Tabla 2. España figura en el grupo de países que menos han incrementado la sofisticación de sus exportaciones durante el siglo 


\begin{tabular}{|c|c|c|}
\hline \multicolumn{3}{|c|}{$\begin{array}{c}\text { ÍNDICE DE SOFISTICACIÓN (EXPY), } \\
2000-2018 \\
\text { (En dólares en PPA*) }\end{array}$} \\
\hline & 2000 & 2018 \\
\hline Japón & $22.471,4$ & $23.623,6$ \\
\hline Alemania & $22.471,4$ & $23.155,8$ \\
\hline Francia & $21.162,8$ & $22.247,8$ \\
\hline Reino Unido & $21.807,3$ & $22.026,5$ \\
\hline Italia & $20.537,3$ & $21.807,3$ \\
\hline Estados Unidos & $21.590,3$ & $21.375,5$ \\
\hline España & $20.130,7$ & $20.537,3$ \\
\hline $\begin{array}{l}\text { Portugal } \\
\text { NOTA: *PPA=P } \\
\text { FUENTE: Worlo }\end{array}$ & $\begin{array}{l}\text { 18.398,1 } \\
\text { der Adquis } \\
\text { ade Soluti }\end{array}$ & $19.341,3$ \\
\hline
\end{tabular}

actual. En ese mismo grupo también se incluyen Italia, Reino Unido y EE UU, pero España es el país que menor índice posee de todos ${ }^{6}$. El elevado peso de las actividades agroindustriales contribuye sin duda a ello, pero no puede constituir una excusa para el estancamiento en este terreno.

Un par de trabajos realizados recientemente, siguiendo la metodología de Product Space elaborada por Ricardo Hausmann y César Hidalgo, han mostrado que incluso una estrategia conservadora de avanzar hacia producciones más complejas, no muy alejadas en requerimientos tecnológicos y habilidades de la mano de obra o de las que actualmente se poseen, permitiría obtener productos más sofisticados en un amplio número de industrias, entre las que se encuentran principalmente las de automoción, química, farmacia, medicamentos (sueros y vacunas),

\footnotetext{
6 El indicador EXPY, propuesto por Hausmann y Klinger (2007), aproxima el valor medio de la productividad del trabajo con la que se obtienen en todo el mundo los productos que un país exporta.
}

plásticos, maquinaria mecánica, maquinaria eléctrica, productos metálicos y productos de minerales no metálicos (Álvarez-López \& Vega Crespo, 2016; Donoso \& Martín, 2017). Incluso en las manufacturas de textil y calzado, hay espacio para aumentos en el grado de sofisticación, como revela una comparación con Alemania (Álvarez et al., 2020). En los dos trabajos citados, se pormenorizan un elevado número de producciones más específicas, encuadradas dentro de cada uno de los sectores mencionados, en las que España podría alcanzar una ventaja comparativa revelada. También lo hace un tercer análisis, el que ofrece en su página web el equipo de The Atlas of Economic Complexity. Algunas de esas producciones se enfrentan a mercados muy expansivos, es el caso de los radares y aparatos de radionavegación, o los instrumentos para medir las propiedades de los líquidos y gases, dentro del apartado de instrumentos científicos; de soldadoras eléctricas, motores y generadores eléctricos, centrifugadoras, máquinas industriales, máquinas-herramientas para trabajar la madera, o máquinas para moler y desfibrar, en el ámbito de la maquinaria; y de reactivos de diagnóstico, abrasivos naturales o artificiales, pegamentos y adhesivos, vacunas y sueros, preparaciones catalíticas, azúcares químicamente puros entre los encuadrados dentro de la química, la farmacia y los plásticos.

En el sector del automóvil, España solo ha logrado aumentar ligeramente la sofisticación de su producción, mediante el impulso de la fabricación de equipos de alumbrado y señalización para el automóvil. Habría conseguido hacerlo en una medida sustancialmente mayor impulsando decididamente la producción de motores, una opción que ahora no deja de tener sentido, en la apuesta por el coche eléctrico.

No solo es importante aumentar la sofisticación de los productos, también su calidad, un rasgo que resulta muy difícil de medir, pero que es de trascendental importancia. Aunque podría presumirse que calidad y sofisticación avanzan conjuntamente, pues ambas descansan 
de manera fundamental en el capital humano, las relaciones entre ellas distan de ser simples.

La transición energética ofrece importantes oportunidades para la ampliación, diversificación y sofisticación de la actividad de los productores nacionales de equipos. No solo en el ámbito de la energía eólica, donde España destaca por la producción de aerogeneradores y surgen importantes oportunidades con la expansión de las plataformas marítimas, sino también en partes y componentes de los equipos utilizados en la obtención de energía fotovoltaica y termosolar (Rodríguez, 2020) y, desde luego, en el desarrollo del hidrógeno como estrategia de provisión de combustibles para los aviones, barcos y camiones, además de para aquellos procesos que requieren elevadas temperaturas, o como medio de almacenamiento de energía. El cambio en la configuración de todos los equipos de transporte, así como de las partes y componentes que incluyen, va a exigir la sofisticación de las actividades de todos sus productores habituales (astilleros y empresas de aeronaves y trenes).

Por otra parte, en el terreno de la digitalización, España, que perdió el tren de la industria electrónica e informática, no puede ni debe resignarse a que se le escape por completo la fabricación de robots, ni de nuevos productos y dispositivos digitales. En este punto, la innovación aparece como un aspecto clave. También la atracción de capital extranjero, a la que se hace referencia a continuación.

En efecto, en el reto de diversificar la estructura productiva española y de incrementar su sofisticación y nivel tecnológico, la inversión extranjera ha de seguir desempeñando un papel clave, como lo ha hecho a lo largo de todo el proceso de industrialización de España. Existe espacio para ello, como ilustran bien los casos de Alemania o el Reino Unido (además de Irlanda), con un peso particularmente elevado de las manufacturas controladas por el capital extranjero. Además, en los últimos años, España, como Francia o Italia, no ha destacado por la inversión exterior atraída a las manufacturas, que ha tendido a concentrarse en Alemania e Irlanda, como pone de relieve la Figura 3.
El grueso de las inversiones dirigidas al sector manufacturero recibidas por España procede del resto de los países comunitarios. A este respecto, la Figura 4, en la que se recoge la evolución del capital invertido por los países de la UE en la industria española en los últimos años, muestra un crecimiento notable del alemán y el británico ${ }^{7}$. El primero, parece haberse debido en una pequeña parcela a la industria automovilística pero, sobre todo, a la farmacéutica, aeronáutica y espacial, y el segundo, sobre todo a las industrias de alimentación y bebidas.

Esto significa que la industria automovilística española sigue atrayendo apoyos, pero no debe olvidarse que se enfrenta a un cambio radical como consecuencia de la expansión del coche eléctrico y la aparición de nuevas formas de movilidad en las ciudades. Mantener la posición de España en el automóvil requiere una apuesta seria de nuestro país por las nuevas tecnologías, y este es, sin duda, uno de los principales retos a los que se enfrenta la industria española a corto y medio plazo. No debe olvidarse que Alemania sigue invirtiendo en el desarrollo de este sector en Hungría, Polonia y Rumanía.

Para diversificar y ampliar el tejido industrial de España es también necesario continuar ensanchando el mercado internacional para los productos españoles. Las manufacturas españolas exportan ya el $40 \%$ de su producción, después de su intenso proceso de internacionalización durante las últimas décadas. Por ello, su facturación se ha hecho ya dependiente de los mercados exteriores. Pero es imprescindible extender estos más allá del ámbito de la UE, con el fin de dotar de mayor estabilidad a las exportaciones y aprovechar mejor las oportunidades que ofrece la expansión del comercio mundial.

En efecto, las exportaciones españolas poseen una diversificación geográfica menor que la de nuestros

\footnotetext{
7 Parte de este crecimiento puede deberse a que previamente parte de la inversión extranjera se realizaba a través de los países de intermediación, Países Bajos y Luxemburgo.
} 


\section{FIGURA 3}

\section{VAB DE LAS MANUFACTURAS DE LA UNIÓN EUROPEA CONTROLADO \\ POR EL CAPITAL EXTRANJERO, 2010-2017}

(En miles de millones de euros)

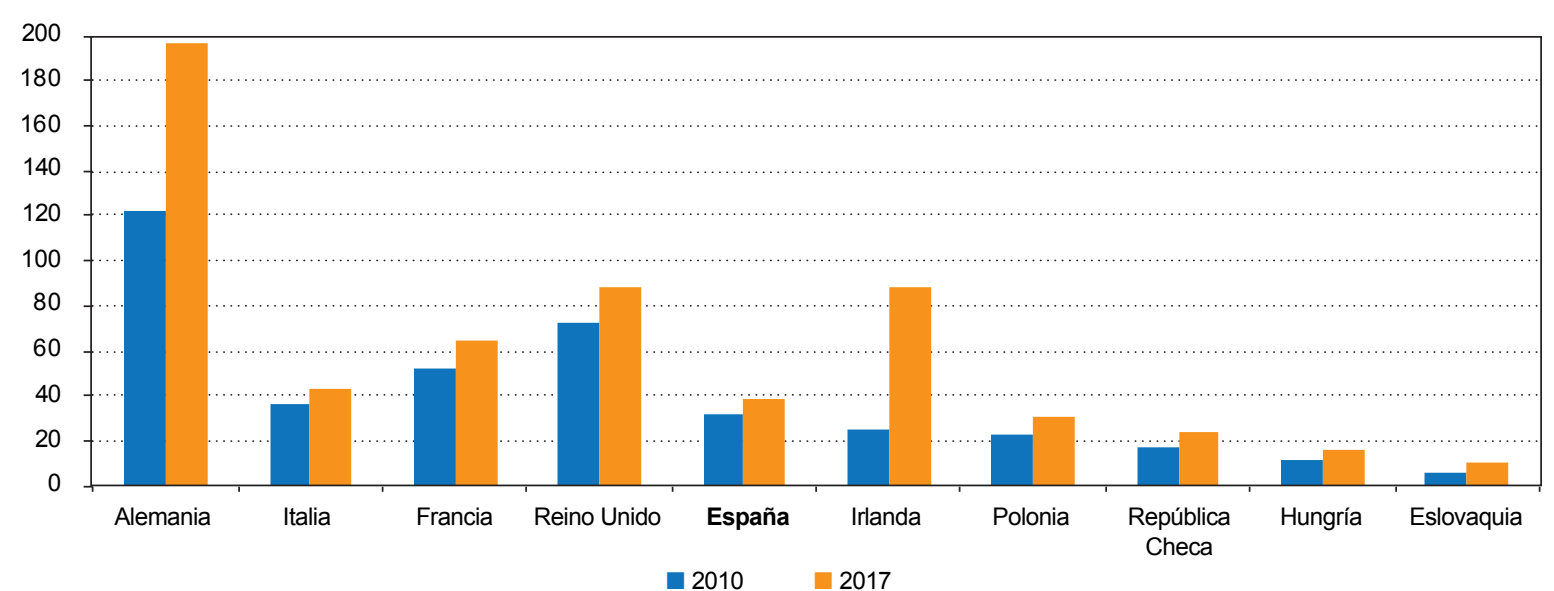

FUENTE: Eurostat, FATS (Foreing Affilia Tes Statistics).

FIGURA 4

STOCK DE INVERSIÓN EXTRANJERA DIRECTA (IED) EN LAS MANUFACTURAS ESPAÑOLAS (En miles de millones de euros)

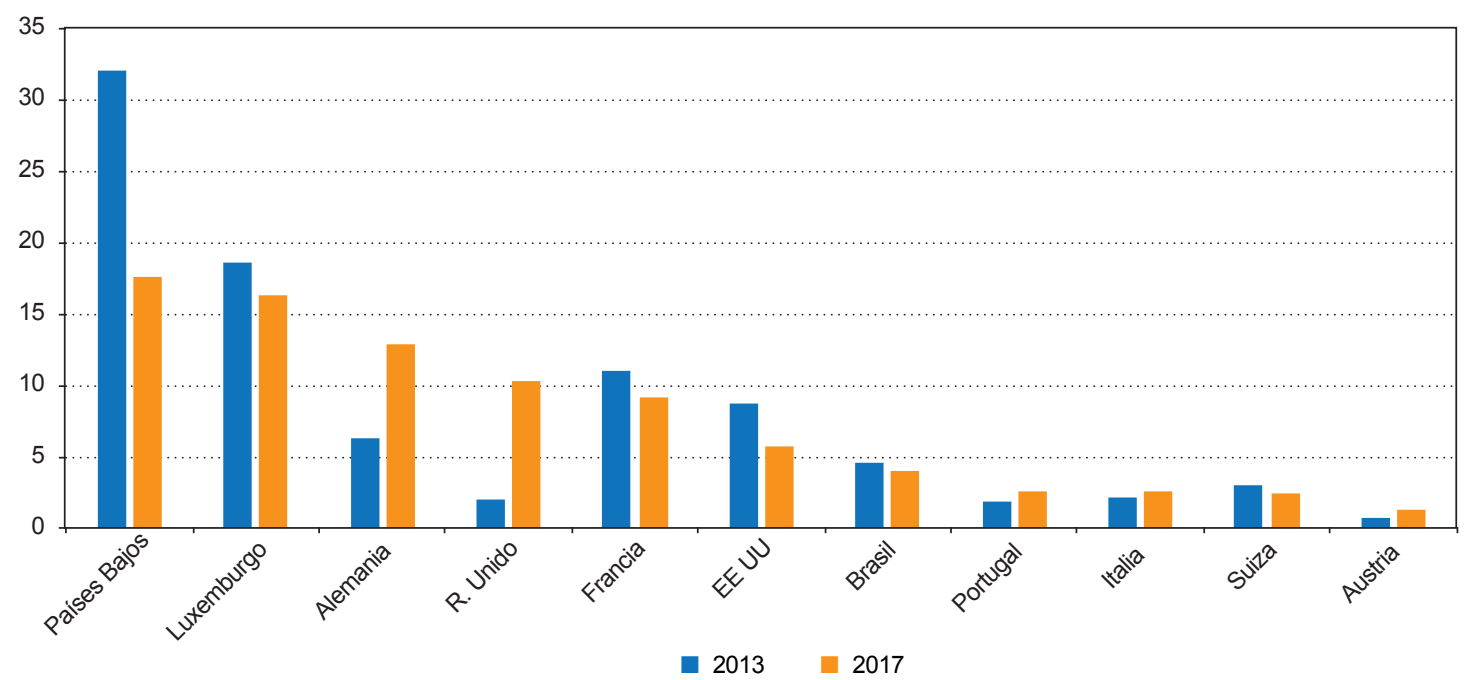

FUENTE: Eurostat. 


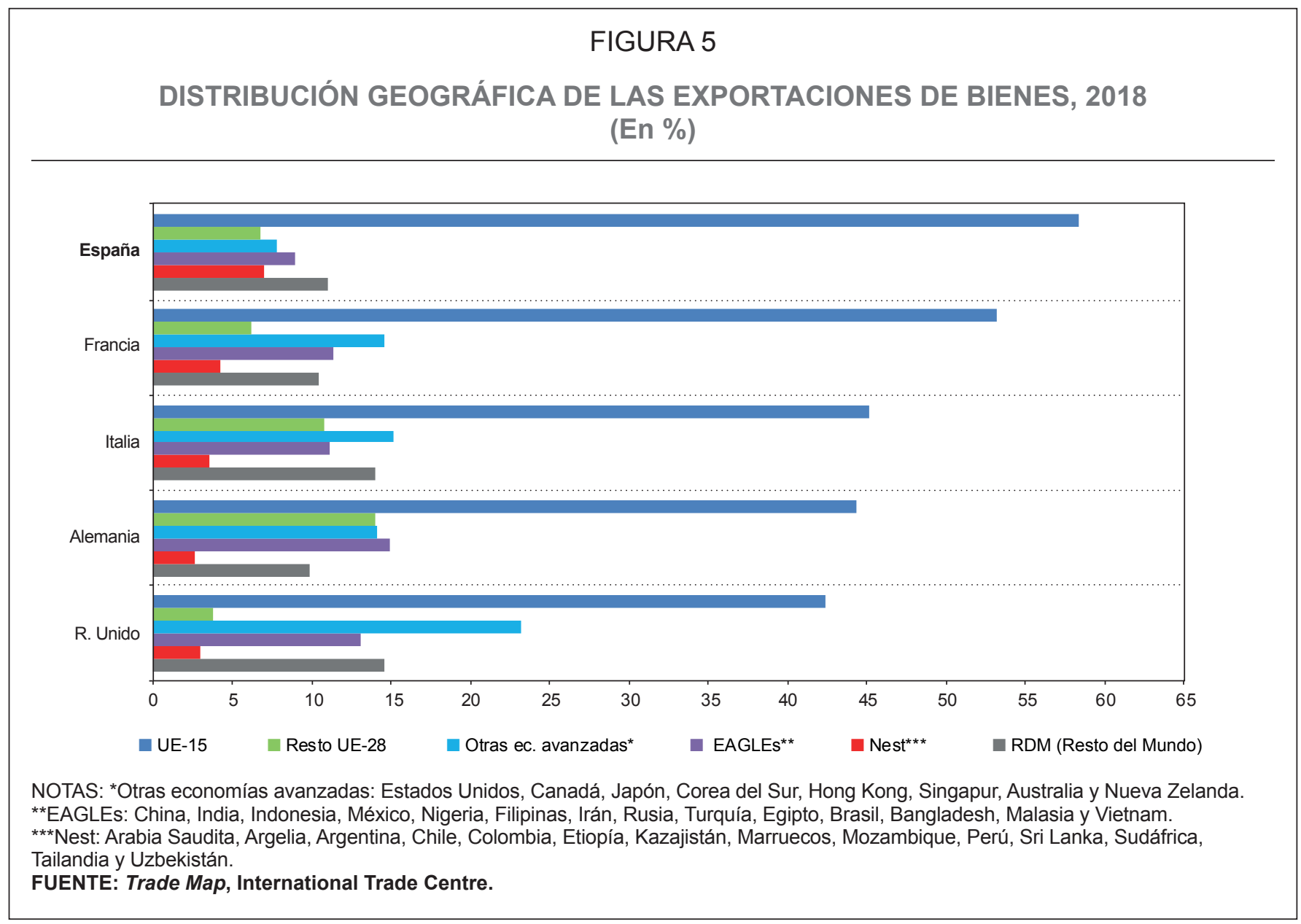

principales socios comunitarios (Figura 5), concentrándose en los más ricos de la UE, y extendiéndose menos al resto (a donde Italia y Alemania llegan más por cercanía geográfica y mayores relaciones de diversa índole). También pecan de una menor presencia en otras economías desarrolladas, fundamentalmente Estados Unidos, Canadá y Japón. Además, los productos españoles alcanzan en una medida menor a los países denominados EAGLEs (por su destacado crecimiento), principalmente China, India, Corea del Sur, Rusia y México. En cambio, poseen una mayor implantación en aquellos otros para los que se prevé un crecimiento económico más rápido en el futuro, los denominados Nest, debido sobre todo a su elevada penetración en Argelia y Marruecos.
La excesiva concentración de las ventas en los mercados comunitarios ha pasado factura a las exportaciones españolas en diversas ocasiones, primero, antes de la Gran Recesión, con la relativa ralentización de la demanda comunitaria (ÁlvarezLópez \& Myro, 2018) y, después, durante ella, debido al acusado impacto que tuvo sobre la UE. Y lo mismo ha ocurrido durante 2020 como efecto de la pandemia (Minondo, 2021).

\footnotetext{
8 Las exportaciones de automóviles se han ralentizado desde 2016, debido a un menor aumento de la demanda en los países comunitarios, en particular en el Reino Unido, pero también como consecuencia de la introducción en 2017 de un nuevo método de homologación de motores (WLTP), que penaliza a los vehículos diésel fabricados en España, que representan un porcentaje elevado de las ventas al exterior (Moral, 2020).
} 
FIGURA 6

PRODUCTIVIDAD DEL TRABAJO EN 2018

(En miles de euros de 2015 por persona empleada)

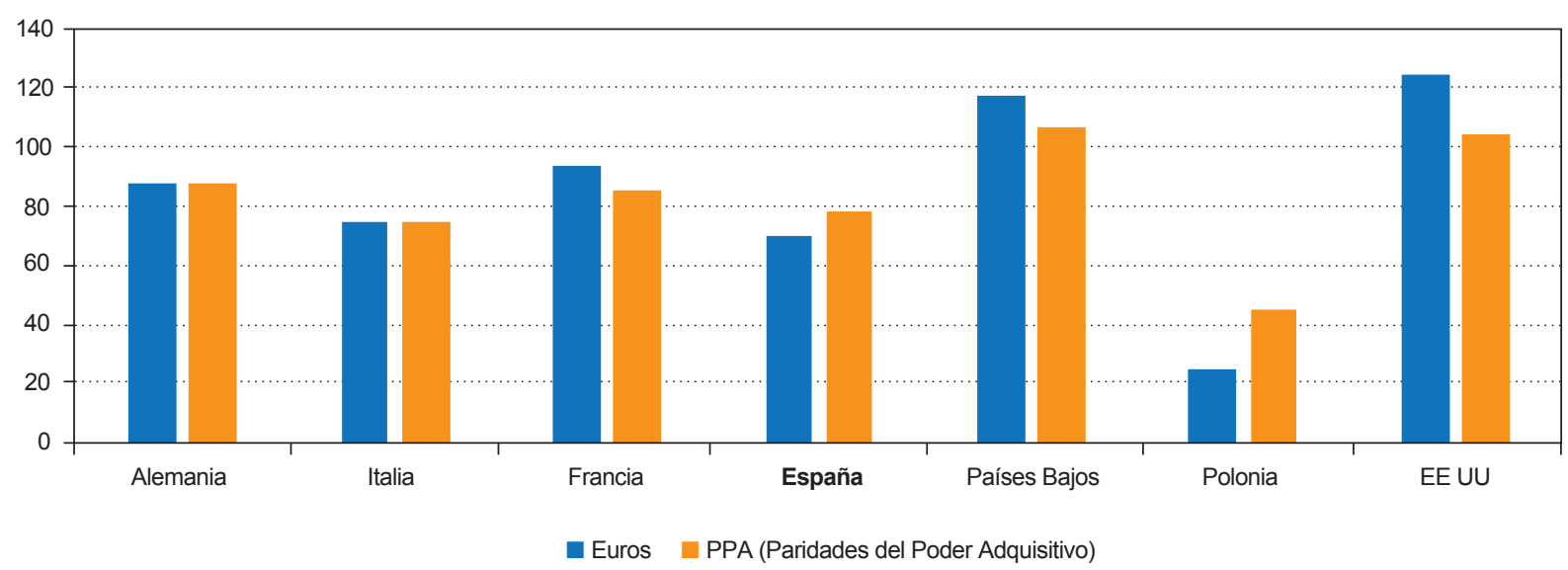

FUENTE: Eurostat.

Por último, todas las transformaciones necesarias que se han mencionado hasta aquí, esto es, una mayor diversificación productiva, la atracción de inversiones exteriores, el sostenimiento de la competitividad interior y exterior de los productos y el incremento de su sofisticación, exigen hacer frente al reto que España posee en lo concerniente a la productividad del trabajo. Es también un reto para los principales países de la UE, pero de menor magnitud. En efecto, en 2018, medida en euros, la productividad del trabajo en España era inferior a la de Alemania, Italia y Francia, si bien ninguna de ellas alcanzaba a la de EE UU (Figura 6). Además, durante los últimos años de recuperación de la Gran Recesión, la productividad del trabajo en España no creció en absoluto. En realidad, el valor que alcanzaba en 2018 era inferior al de 2015. Esto es algo que no ha sucedido en los demás países con los que se compara aquí. Aunque también es cierto que el crecimiento de esta variable en España entre 2000 y 2018 superó al logrado en Alemania, Francia o Italia.
El problema de la productividad transciende a las manufacturas y afecta también a aquellos servicios que son claves en la competitividad de estas, lo que no ha impedido hasta ahora una rápida expansión de su producción y sus exportaciones, como se ha señalado ya con anterioridad. En la Figura 7 se muestra el avance en España, entre 2001 y 2016, de la eficiencia productiva de las manufacturas, medida a través de la Productividad Total de los Factores (PTF). Se compara con otros dos países, uno muy industrial (Alemania) y otro intensivo en servicios avanzados (Reino Unido). En realidad, el comportamiento de la eficiencia en las manufacturas españolas es sobresaliente comparado con el de los sectores de servicios, si se exceptúa el caso de los de información y comunicaciones. Por otra parte, puede observarse cómo las producciones de maquinaria eléctrica y electrónica destacan, dentro de las manufacturas, por el ascenso de su PTF.

Las causas de este pobre comportamiento de la PTF no parecen encontrarse tanto en una falta de capital físico, o de activos tangibles en las empresas, como 
FIGURA 7

CRECIMIENTO DE LA PTF EN DIFERENTES INDUSTRIAS

(Tasas anuales de variación para el periodo 2001-2016)

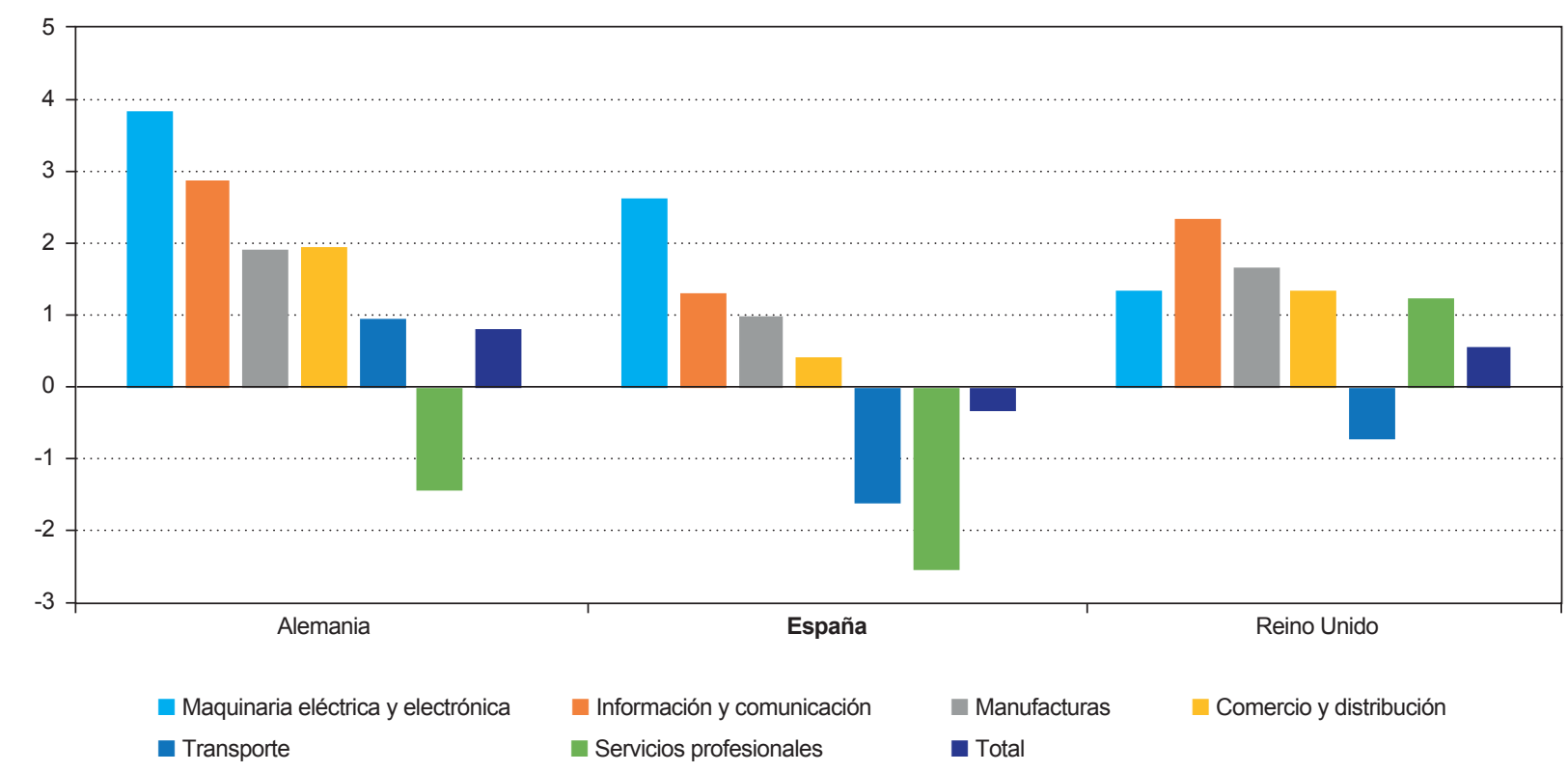

FUENTE: EUKLEMS.

de capital humano y tecnológico, dos factores claves, que en los balances de las empresas se incluyen dentro de la rúbrica general de activos intangibles. Estos activos pueden dividirse, siguiendo a Corrado et al. (2016) en tres clases, software y bases de datos, tecnología (propiedad) y competencias económicas, incluyéndose en este último rubro formación de los trabajadores, marketing, creación de marcas y activos de gestión empresarial (calidad de la gestión). En la comparación con otras economías, España destaca por el bajo peso de estos activos intangibles sobre su PIB, especialmente los de innovación y los de competencias económicas. EE UU se revela como el país que más activos de este tipo acumula en proporción a su producción. La situación de Italia tampoco es muy confortable, añadiéndose en este caso un menor desarrollo de la digitalización, algo que este último país comparte con Alemania (Myro, 2019).

\section{El papel de la política industrial}

Para abordar con éxito los retos antes mencionados, se requiere un gran protagonismo del Estado en el desarrollo industrial, dando un giro radical a la concepción de la política industrial que ha prevalecido durante los últimos 30 años, no solo en España, sino también en otros países europeos.

Afortunadamente, este giro se formula ya con nitidez en la nueva estrategia comunitaria gestada con anterioridad a la pandemia del coronavirus, y se ha visto muy considerablemente reforzado con esta. En efecto, en los últimos años, desde diferentes instancias comunitarias, se ha reclamado un nuevo papel del Estado en el desarrollo de la industria, más ambicioso y activo. No solo lo ha hecho de forma reiterada el Consejo de la Unión Europea, llamando a una verdadera política 
industrial, comprensiva y de largo plazo, con la vista puesta inicialmente en 2030, que subraye las oportunidades existentes y afronte los retos pendientes (Consejo de la Unión Europea, 2019), sino que también lo han hecho los Gobiernos alemán y francés, que firmaron en febrero de 2019 un manifiesto conjunto por la industrialización ${ }^{9}$, en el que prometían apoyo a los proyectos de alta tecnología muy arriesgados (salud, clima, seguridad y tecnología digital), financiación para las startups y la innovación, e impulso a la fabricación de baterías eléctricas, con el fin de despejar por completo el camino hacia el coche eléctrico. Además, apostaban por la Inteligencia Artificial, aspirando a lograr en este ámbito una posición de liderazgo para Europa. Finalmente, la European Round Table of Industrialists (ERT), una institución que agrupa a más de 50 empresas europeas de gran dimensión ha llamado en varias ocasiones a los Gobiernos europeos a crear condiciones favorables para la competencia de las empresas europeas a escala global.

Estas llamadas no solo han sido una respuesta al lento desarrollo de la industria europea, sino también a los muchos análisis que otorgan al Estado un espacio más amplio de actuación en el terreno industrial del que se le ha ofrecido hasta ahora, así como a las experiencias exitosas de los países asiáticos, China en particular, en sus estrategias industriales y de desarrollo tecnológico (Krugman, 1992; Rodrik, 2004; Chang et al., 2013; Aghion, 2009; Mazzucatto, 2014; Myro, 2016).

La pandemia ha dado fuerza a todos estos planteamientos. No solo ha puesto de relieve la elevada dependencia que tiene la UE de los suministros chinos, sino también la importancia de las tecnologías digitales, así como la rezagada posición europea en el análisis de datos y el desarrollo de la Inteligencia Artificial. La respuesta ha sido el despliegue de un amplio plan de apoyo gubernamental a las empresas en todos los países, y

9 A Franco-German Manifesto for a European industrial policy fit for the 21st Century. de forma muy singular y extensa en Alemania, con el fin, no solo de sostener sus ingresos y volúmenes de empleo, mientras se enfrenten a los efectos negativos de la pandemia, sino también de posibilitar y facilitar un gran salto hacia adelante en la dimensión y competitividad de la industria europea, poniendo énfasis en la digitalización y la descarbonización. El Fondo Europeo de Recuperación Next Generation EU es la última, pero no menos importante pieza, dirigida a facilitar la incorporación a este salto de los países más afectados por la pandemia, y con menor capacidad de gasto público para afrontarlo, como es el caso de España.

En el logro de los dos objetivos de alcance europeo mencionados, las dos transiciones industriales, la energética y la digital, la intervención pública resulta imprescindible para coordinar la realización simultánea de las múltiples inversiones que son necesarias, que involucran diferentes actividades y empresas, y conseguir armonizar los ritmos de evolución de la oferta y la demanda interiores.

La compleja transición hacia un nuevo modelo de movilidad basada en las energías renovables reclama ya con urgencia esta coordinación pública en España; basta con contemplar el escaso relieve que hoy ofrecen, en términos comparados con otros países europeos, tanto la producción de coches eléctricos, como el despliegue de la red de puntos de recarga. La transición en la movilidad posee grandes economías de aglomeración, con interdependencias acusadas entre actividades extractivas, manufactureras y de servicios, y con importantes retos tecnológicos y elevadas exigencias de cualificación laboral. Su ejecución exige pues el despliegue de una eficaz coordinación pública, que guíe la toma de decisiones sobre las opciones fundamentales hoy planteadas, e impulse la innovación, en estrecho contacto con las empresas y con todos los actores involucrados.

En lo que toca al sector clave del automóvil, tal coordinación debe facilitar las decisiones acerca de dónde, cuándo y cómo localizar en España la producción de baterías para los coches eléctricos y sopesar 
las posibilidades de avanzar hacia la producción de motores. Las baterías desempeñan un papel crítico, tanto en el impulso de la producción como en el valor añadido obtenido por vehículo (Sholtes Ruiz, 2019). Por otra parte, su fabricación exige la incorporación de muchos más semiconductores y componentes electrónicos, que sofistican el vehículo obtenido y preparan el avance hacia el coche automático. También debe facilitar las decisiones acerca de cómo y a qué ritmo desplegar la red de recarga de esas baterías, y en especial la de recarga rápida; son decisiones que habrán de sincronizarse en alguna medida con las que determinen el ritmo al que se quiere ir cambiando la producción actual, transitando desde el actual escenario de predominio de la producción de coches con motores diésel hacia otro en el que solo se produzcan vehículos con motores híbridos y eléctricos. Estas decisiones no solo afectan a los fabricantes principales sino a toda la amplia red de suministradores, y al adoptarlas deben evitarse los extremos, es decir, tanto aquellos ritmos que puedan dejar obsoletas antes de tiempo las instalaciones actuales, como aquellos otros que dificulten la transición perseguida. Es claro que hasta ahora ha predominado un sostenimiento del statu quo, pero acompañado de una gran incertidumbre respecto a los pasos a dar en el futuro, lo que ha afectado negativamente a la demanda de vehículos por parte de los consumidores, y por consiguiente a la rentabilidad de las empresas encuadradas en esta industria. En estas decisiones, la coordinación con las casas matrices de las empresas y los Gobiernos de los países en los que residen resulta clave y, por tanto, también aquí es decisivo el papel del Gobierno. Debe tratar de conseguir que las empresas españolas se mantengan en un lugar destacado en la nueva estrategia europea.

En los otros sectores de material de transporte, aeronáutico y espacial, material ferroviario y buques, la coordinación pública es también necesaria para definir una estrategia de transición hacia equipos más veloces y seguros, también frente a los virus, y con menores emisiones de $\mathrm{CO}_{2}$, basados en el hidrógeno renovable o en otros combustibles sin emisiones ${ }^{10}$.

El cambio de modelo de generación energética exige así mismo un gran esfuerzo de coordinación pública, pero en este sector tal coordinación ha sido una característica más visible y permanente (como también lo ha sido en otros sectores de servicios públicos y de suministros en red), lo que no quiere decir que no se enfrente hoy a nuevos retos de gran relieve.

En la transición digital, el foco central ha de ser el impulso de la generación y explotación de datos, facilitando el acceso público a ellos, y el desarrollo de la Inteligencia Artificial. En este caso, la intervención pública es obligada por las externalidades de learning by doing de estas actividades. En efecto, la explotación de los datos genera conocimientos que abaratan los procesos productivos, amplían el número de consumidores y favorecen el desarrollo de nuevos productos. $Y$ todo ello redunda en nuevos datos que reinician el círculo virtuoso. Pero estos beneficios no son visibles a priori, pues dependen del propio trabajo con los datos, es decir, del aprendizaje con la práctica. Tampoco son conocidas las posibilidades que existen de apropiarse de los resultados de este trabajo por parte de quien lo emprende, lo que inhibe la inversión del sector privado, y hace obligada la intervención pública (HM Government, 2018; OCDE, 2015). Además, las grandes empresas con posibilidades de crear y explotar amplias bases de datos gozan de ventajas competitivas que pueden traducir en poder de mercado, algo que ya ocurre hoy en el caso de las denominadas Big Tech companies. Las norteamericanas controlarían hoy cerca del $90 \%$ de los datos del mundo occidental. Por esta razón, la Comisión Europea trata de poner actualmente en marcha un proyecto de construcción de una amplia base de datos de acceso libre, mediante una acción especial, similar a la que abrió el camino a la cooperación europea en el

\footnotetext{
$10 \mathrm{El}$ anuncio de diversos proyectos para instalar y poner en funcionamiento diversas plantas de hidrógeno renovable a partir de 2021 es una excelente noticia que parece indicar un acortamiento de los largos plazos inicialmente previstos para disponer de esta nueva fuente de energía.
} 
sector aeronáutico. Esta actuación es crucial para facilitar el acceso a menor coste de las empresas pequeñas y medianas a una variedad creciente de software y servicios digitales (cloud computing), con potenciales efectos positivos sobre su productividad, así como sobre la calidad y variedad de sus producciones. $Y$ no solo de las pequeñas empresas ${ }^{11}$. Como señala Marin (2020), Volkswagen obtiene hoy el software que necesita de Google o de empresas chinas establecidas en Alemania, porque no existen productores nacionales de relieve. Esta precaria situación dificultará su avance en el futuro, sobre todo cuando aspire a producir un coche sin conductor, que ha de basarse en múltiples y excelentes conexiones digitales.

España tiene que subirse rápidamente a este tren comunitario. Por de pronto, los presupuestos comprometidos por España en su Estrategia de Inteligencia Artificial son reducidos (350 millones), si se comparan con los del conjunto de la UE (20.000 millones), habida cuenta del peso del PIB español en la UE (8,4 \%). Los presupuestos comunitarios tampoco parecen muy acordes con las ambiciones del proyecto. Pero, además, España parte de una posición más rezagada que los líderes europeos en las capacidades de sus empresas y trabajadores para introducirse en el terreno de la Inteligencia Artificial. Es obvio que España no puede permitirse perder el tren de la digitalización.

Más allá de los dos importantes objetivos transversales examinados, la política industrial posee hoy un amplio potencial de actuación, dadas las externalidades positivas que el desarrollo de la industria y los servicios avanzados ofrecen (aglomeración, información, conocimiento tecnológico y learning by doing), que no son siempre fáciles de identificar ni de aprovechar (Maloney \& Nayyar, 2017).

Empezando por las economías de aglomeración, las Administraciones públicas deben coordinar

\footnotetext{
11 También se ha iniciado una regulación del espacio digital europeo, con la adopción de la Ley de Servicios Digitales (Digital Services Act, DSA) y la Ley de Mercados Digitales (Digital Markets Act, DMA).
}

el despliegue de empresas en cada territorio, para asegurar que se extraen los beneficios de las interdependencias y complementariedades que existen entre ellas en diferentes terrenos (infraestructuras, mercados, tecnologías y cualificación de la mano de obra) (Rodrik, 2004; Krugman, 1992; Myro, 1994). Como señalara Paul Krugman (1992), de la importancia de las economías de aglomeración dan cuenta los sistemas productivos locales existentes, que en el caso de España han adquirido relevancia en las industrias de automoción, maquinaria, química y plásticos, alimentos, textil y confección, cuero y calzado y productos para la casa (Boix-Domenech \& Trullén, 2011). No parece, sin embargo, que tales sistemas necesariamente hayan de proliferar más en unos sectores que en otros. Podría ser que fueran sobre todo un instrumento de explotación de externalidades con utilidad para toda aquella actividad en la que un país consigue una ventaja relativa revelada (RodríguezClare, 2004).

En España, la intervención pública dirigida a coordinar el despliegue territorial de las actividades industriales fue perdiendo relieve desde el principio de la década de los años ochenta, primero por las convulsiones de la transición política, y después, por el rechazo al intervencionismo estatal y por el traspaso de las responsabilidades de fomento industrial a las comunidades autónomas, sin asegurar mecanismos efectivos de coordinación con la Administración central. Solo algunas Administraciones regionales, principalmente las de la Comunitat Valenciana, Cataluña, el País Vasco, Castilla-La Mancha y Castilla y León, siguieron desarrollándolas con un apreciable relieve, multiplicando el número de sistemas productivos locales de gran empresa, y de distritos industriales compuestos por pyme, mientras que las restantes lo intentaron con desigual fortuna (Boix-Domenech \& Trullén, 2011) ${ }^{12}$.

\footnotetext{
12 Los distritos industriales españoles crean el $21 \%$ del empleo manufacturero, el 30,6 \% de las innovaciones, con una ratio de 337 por empleado, 47 \% por encima de la media nacional (Boix-Domenech, 2008)
} 
La disminución de las tareas de coordinación pública podría quizá explicar algo del escaso desarrollo que ha logrado España en algunas producciones más sofisticadas, principalmente las electrónicas, o de la paulatina disminución de tejido industrial en la Comunidad de Madrid, una comunidad que podría ilustrar bien los efectos del gradual abandono de la intervención estatal en el desarrollo de la industria, que acabaría por provocar el desmantelamiento de IMADE y PROMOMADRID, dos agencias clave ${ }^{13}$.

Con respecto a las externalidades ligadas a la información y el desarrollo tecnológico, la diversificación y sofisticación del tejido industrial dependen de forma crucial de su aprovechamiento. Mientras que el apoyo al emprendimiento puede explotar la información que los individuos y empresas poseen acerca de nuevos productos y procesos productivos -el self-discovery al que se hace referencia en Rodrik (2004)_, la política de ciencia y tecnología es el núcleo fundamental de la política industrial de un país desarrollado, e incluye como uno de sus aspectos clave el apoyo a la innovación de las empresas, justificado por las externalidades positivas que este ofrece y la reducida capacidad que poseen los empresarios para apropiarse de los beneficios de la innovación. Esto quiere decir que la ausencia de un apoyo público suficiente a la innovación conduce a un desarrollo de esta inferior al deseable.

El papel de los Gobiernos españoles en el esfuerzo tecnológico y la innovación ha sido particularmente pobre, y como consecuencia de ello, España se ubica en el grupo de «innovadores moderados», entre los países de la UE, un grupo en el que convive con las economías del centro y el este de Europa, que poseen

\footnotetext{
${ }^{13}$ Esta comunidad, no solo ha visto reducirse de forma muy rápida el peso de las manufacturas en el PIB, hasta niveles muy bajos, del $6,5 \%$ en 2019, inferiores a los de las regiones desindustrializadas prematuramente (Barandiaran et al., 2019), sino también el VAB obtenido, que en 2019 era tan solo un $80 \%$ del que alcanzó en el año 2000 , mientras que el empleo manufacturero se habría reducido un $40 \%$ en el mismo periodo. No obstante, el caso de Madrid es complejo, porque a la apuesta por servicios avanzados, se ha unido el traslado de parte de su industria a Guadalajara y otras provincias colindantes.
}

niveles de renta per cápita sensiblemente inferiores a los españoles. Italia es el único país, de entre los desarrollados, que acompaña a España en este grupo. No se trata solo, ni principalmente, de un problema de recursos públicos, sino de concepción del papel del Estado en el Sistema de Innovación. Se concibe como pasivo, muy lejos del papel coordinador y definidor de objetivos y misiones que lo caracteriza en los EE UU $y$, en menor medida, en Alemania (Mazzucato, 2014).

Así pues, en estrecha cooperación con el sector privado, las acciones gubernamentales deben adentrarse con intensidad y capacidad de liderazgo en aquellos campos de la innovación que poseen niveles de riesgo inasumibles por las empresas en solitario, fomentando la cooperación, y enmarcándose de forma clara en los planes europeos, que hoy prometen una gran ambición. El número de campos de innovación en que la presencia pública es necesaria tiende a crecer al hilo de los nuevos cambios tecnológicos, pero son claros los de salud y medicina, nuevos materiales, energía, seguridad e inteligencia artificial. Y desde luego, el de medioambiente, ya que será difícil alcanzar los objetivos planeados de descarbonización para 2050 sin tecnologías para la captación del carbono existente en la atmosfera (Yergin, 2020).

El extendido diagnóstico de que la actividad innovadora en España es reducida porque las empresas no pueden asumir sus costes, desconfían de sus potenciales beneficios o prefieren tecnologías accesibles no es acertado. Con un tejido empresarial en el que predominan las pymes, no hay innovación sin un compromiso firme del Estado en su desarrollo.

En todo caso, en los apoyos a la innovación, debe prestarse especial atención a las empresas de tamaño mediano, definiendo este con un amplio criterio, quizá el comprendido entre 150 y 1000 trabajadores, un rango superior al que se considera habitualmente en el espacio de la UE. Mientras que las empresas pequeñas acaban beneficiándose de las nuevas tecnologías con relativa facilidad, a través de las políticas de difusión tecnológica seguidas, dado que se encuentran lejos de la frontera de eficiencia, 
las empresas medianas, que se encuentran más cerca de ella, requieren de un esfuerzo tecnológico de especial relieve para poder avanzar (Bahar, 2018). Estas empresas, por lo demás, desempeñan un papel fundamental en el mantenimiento de la competencia en los mercados.

En la búsqueda de la diversificación y sofisticación del tejido industrial, son también de gran importancia las acciones dirigidas a facilitar a las empresas el acceso a los mercados exteriores y a atraer inversión extranjera. Ambas actividades dependen del sector público. El conocimiento de los mercados exteriores, que habitualmente se denomina «inteligencia de mercado», es un activo esencial para el éxito de la penetración en ellos, pero no suele ser muy cuantioso en ausencia de apoyo público, porque las empresas no dedican recursos a algo de lo que difícilmente se apropiarán. Y en el caso de la atracción de capital extranjero, son muchos y de índole diversa los beneficios que se obtienen de una acción de promoción pública, comenzando por el acceso a la tecnología exterior.

En ambos campos, los Gobiernos españoles han desplegado muchos más esfuerzos que en el de la investigación tecnológica y, como consecuencia, conseguido resultados importantes. Son, sin embargo, mucho más notorios estos en el ámbito de la exportación que en el de la atracción de inversiones, lo que quizá tiene que ver con la eliminación de la agencia Invest in Spain. En acciones donde un servicio adaptado a las características de las empresas que se quieren atraer resulta clave, la conversión de esa agencia en una dirección ejecutiva, dentro de un organismo cuya finalidad principal es la de promoción de la exportación, como es el ICEX, no parece la estrategia más adecuada. Aparte de que desoye uno de los diez principios principales de actuación señalados por Rodrik (2004): no toques lo que funciona bien. Por otra parte, la reciente adopción de mecanismos de escrutinio y control para la entrada de IED, siguiendo directrices comunitarias y con el objetivo de defender la autonomía tecnológica y proteger a los sectores que se consideren estratégicos, podría convertirse, merced a una gestión poco ágil y atenta, en una barrera burocrática adicional que dificulte el acceso de nuevas multinacionales al territorio español. Ya existen signos de ello (Scheifler, 2020).

Finalmente, las actuaciones públicas deben buscar el impulso de la productividad del trabajo. El software y los datos, como la innovación, forman parte del capital intangible de la empresa, que resulta clave para el avance de su productividad. Pero esta también depende de otros intangibles, como la formación de sus trabajadores, una actividad que también debe ser apoyada con fondos públicos, dado que la empresa no puede apropiarse completamente de los beneficios que ofrece. Así mismo, el desarrollo de otros intangibles como el marketing y los estudios de mercado, la creación de marcas, colectivas e individuales, o los activos organizacionales y de gestión requieren del apoyo público. Muchas pymes, sobre todo las más pequeñas, tienen dificultades para acumular estos activos, de forma que los Gobiernos regionales y el Gobierno nacional deben ofrecer su capacidad de coordinación para facilitar el acceso de estas empresas a ellos. De otra forma, no se aprovechará todo el potencial productivo que estas empresas poseen.

\section{La instrumentación de la política industrial}

Para dar el giro propuesto a la política industrial, los Gobiernos españoles necesitan realizar dos cambios fundamentales. El primero, el de su concepción acerca del papel del Estado y las demás Administraciones públicas en la economía y, el segundo, el de los instrumentos de intervención.

Con respecto al primero de estos aspectos, el papel de las Administraciones públicas en la economía, y más específicamente, en la industria, durante los últimos 40 años ha predominado una manera de concebirlo como pasivo y dependiente de las demandas de las empresas privadas, con el resultado de una atención preferente de las acciones públicas hacia los lobbies y grandes empresas, dada la poca vertebración del tejido 
empresarial español, esto es, su estrecho marco de alianzas y relaciones, que hace difícil la canalización de las aspiraciones y necesidades del conjunto de las empresas de la industria manufacturera, sobre todo de las pymes, hacia la Administración pública. Pues bien, la concepción que debe predominar hoy es la de unas Administraciones públicas que coordinen el despliegue de las actividades industriales, en cooperación continua y estrecha con las empresas, los sindicatos y otros agentes y, así mismo, lideren el desarrollo tecnológico y la innovación, tras definir sus líneas estratégicas en diálogo continuo y efectivo con la Universidad y otros organismos de investigación. La promoción exterior y la atracción de inversiones extranjeras, así como la reestructuración de las empresas y sectores en crisis ha de tener así mismo cabida en este nuevo marco de cooperación. Este, por otra parte, debe ser construido, lo que requiere también de la Administración pública la promoción de un verdadero espacio de interlocución con las empresas, privilegiando sus asociaciones más representativas, y contribuyendo a favorecer sus interrelaciones, mediante la creación de observatorios y unidades de forsight.

Las razones por las que España no cuenta con un sector industrial suficientemente integrado probablemente residen, de una parte, en la elevada importancia de las compañías multinacionales, con menor necesidad de implicarse en el tejido productivo español y, de otra, en la gran dualidad existente, dentro del ámbito empresarial, entre un conjunto de empresas muy grandes y productivas, y una pléyade de microempresas, de productividad reducida, con pocos intereses en común con las primeras. Pero a estas dos razones se añade una tercera, la adopción por parte del Gobierno nacional y de los Gobiernos regionales de una notable distancia con respecto al mundo de los negocios, que en realidad ha favorecido una excesiva influencia de las empresas muy grandes.

El cambio en la concepción del papel de las Administraciones públicas en la industria ha de ir acompañado de cambios en su estructura organizativa.
Si los Gobiernos nacional y regional han de ser capaces de discutir y valorar las propuestas recibidas de las asociaciones empresariales y sindicales, de asumir complejos programas de coordinación de actividades y de formular iniciativas de progreso en la producción, la innovación, los mercados exteriores o la atracción de capitales exteriores, han de incrementar su capacitación técnica. Han de disponer de más personal bien equipado técnicamente (en análisis industrial, de mercados y financiero) y debe construirse un marco de cooperación permanente entre las esferas central y autonómica, apenas esbozado hoy. Y desde luego, deben multiplicarse los organismos de cooperación y de conexión público-privada especializados, imitando a algunos ya existentes que funcionan bien, el ICEX, el CDTI o ENISA, y resucitando algunos de los eliminados en los últimos años. En el marco de una estrecha cercanía con las empresas, tales organismos deben ayudar a definir las perspectivas de futuro y las opciones estratégicas disponibles para cada una de las actividades manufactureras, así como participar en su despliegue e implementación, especializándose horizontalmente y en algunas ocasiones, si se considera necesario, sectorialmente (automóvil y aeronáutica, por ejemplo).

La concepción pasiva de la Administración pública prevaleciente hasta ahora ha privatizado, en las consultoras, sobre todo en las más grandes, parte del trabajo de análisis, definición de estrategias y diseño de actuaciones que corresponde a una Administración pública de nuevo cuño, que quiere saber y entender de industria, e intervenir de forma decisiva en su desarrollo. Por esta razón, cuando surge ahora la necesidad de administrar las ayudas que se recibirán del fondo Next Generacion EU, el Gobierno recurre a tales consultoras para definir y gestionar los proyectos a los que se dirigirán esas ayudas. La renuncia a construir equipos especializados y con capacidad de gestión por parte de las Administraciones públicas ha sido también uno de los factores que ha impulsado la continua transferencia de altos funcionarios hacia las 
empresas consultoras. Por lo demás, resulta obvia la existencia de un conflicto de intereses en la contratación sistemática de estas por parte de los poderes públicos, puesto que también son contratadas por las empresas privadas para los mismos fines.

Para la gestión de los fondos europeos, los Gobiernos españoles también van a recurrir a sociedades con participación público-privada de nuevo cuño, con el posible inconveniente de que sea la empresa privada la que acabe liderando los proyectos, dado que las Administraciones públicas carecen de personal especializado con el que participar en tales entidades que, por otra parte, podrían prolongar su vida más allá del tiempo de duración del proyecto sin funcionalidades claras. Resulta obvio que deberían constituirse entidades menos perecederas y con cometidos claros, y contratar personal especializado para su gestión.

Buscando ampliar las opciones para configurar un marco de intervención pública más eficaz, se acaba de abrir también la posibilidad de crear nuevas agencias públicas, que había sido cerrada en 2015 por el Gobierno de Mariano Rajoy. Es una decisión muy afortunada, pues las agencias son el principal brazo de actuación de una Administración pública activa, y deben crearse sin miedo a que sean utilizadas para fines espurios. Solo hay que garantizar que existen los adecuados mecanismos de control. Señala Marin (2020) que Alemania necesita una DARPA, refiriéndose a la influyente agencia norteamericana de innovación en el área de la defensa. España también la necesita, pero podría comenzar por tener una SIBR (Small Business Innovation Research), dirigida a apoyar a las pequeñas y medianas empresas innovadoras, o tal vez por construir una Agencia Industrial, con diferentes cometidos y especializaciones, no exclusivamente orientados hacia las manufacturas.

\section{Conclusiones}

En este artículo se ha examinado la evolución de la industria durante 2020, resaltando el notable impacto que ha tenido la pandemia en el producto industrial, alejándolo aún más del nivel alcanzado en 2008, que aún no había recuperado. También lo ha alejado de los niveles de los socios comunitarios.

Este impacto negativo hace aún más necesario contar con una estrategia ambiciosa de reindustrialización, para la que se han propuesto tres objetivos, una vez superadas las restricciones derivadas de la pandemia: i) diversificar y sofisticar las producciones manufactureras, con el concurso de la inversión extranjera; ii) aumentar la penetración en los mercados exteriores, ampliando su número; y iii) elevar la productividad del trabajo, clave de la competitividad exterior. Son objetivos que han de extenderse también a los servicios avanzados, puesto que estos favorecen el desarrollo de la industria, especialmente los digitales. La política industrial debe pues cuidar también estos servicios fundamentales.

Para conseguir los objetivos señalados, los Gobiernos nacional y regional han de dar un giro importante a sus políticas industriales, haciéndolas más ambiciosas y menos pasivas, buscando un compromiso más profundo con el desarrollo industrial que el mantenido hasta ahora. Eso significa cambiar la concepción del papel del Estado en la economía y reorganizar la base institucional de actuaciones. Es un planteamiento en línea con el que están realizando los principales países europeos y que se verá facilitado por la ayuda que España va a recibir del Fondo de Recuperación Europeo.

La nueva política industrial que los retos tecnológicos y medioambientales demandan hoy, y el definitivo impulso que la industria española requiere para superar los efectos de la pandemia, y consolidarse como una industria fundamental en el marco de la UE, debe construirse sobre una mejor articulación institucional de lo público (Gobierno central y Gobiernos regionales), y una mayor cercanía entre lo público y lo privado en la definición de objetivos y actuaciones, con la universidad actuando como un nodo imprescindible. Una Administración bien cualificada y pertrechada de organismos de intervención debe perder su miedo a verse involucrada en intereses espurios cuando asume un 
mayor contacto con el sector privado, y debe exigir y promover una mayor cohesión entre las organizaciones integrantes de este, pidiéndole de forma incesante que formule y defina sus necesidades y planes de actuación a medio y largo plazo.

\section{Referencias bibliográficas}

Aghion, P. (2009). Some thoughts on industrial policy and growth. OFCE, Documento de Trabajo n. ${ }^{\circ} 9$.

Álvarez-López, M. ${ }^{a}$ E. \& Vega Crespo, J. (2016). La promoción exterior. En R. Myro (dir.), Una nueva política industrial para España, cap. 10 (pp. 153-173). Consejo Económico y Social España.

Álvarez-López, M. ${ }^{a}$ E. \& Myro, R. (2018). Diversificación de mercados y crecimiento de la exportación. Papeles de Economía Española, 158, 90-101.

Álvarez-López, M. ${ }^{a}$ E. \& Vega Crespo, J. (2020). Comercio e Inversión Extranjera Directa. En R. Myro \& G. Solana (dirs.), Internacionalización Ibérica, España y Portugal en la economía mundial 2020, Parte 1 (pp. 32-78). Cátedra Global Nebrija Santander.

Álvarez-López, M. ${ }^{a}$ E., Myro, R. \& Serrano, J. (2020). Complejidad económica de las exportaciones españolas. Información Comercial Española (ICE), Revista de Economía, 913, 125-139. https://doi.org/10.32796/ice.2020.913.6985

Bahar, D. (2018). The middle productivity trap: Dynamics of productivity dispersion. Economics Letters, 167, 60-66.

Barandiaran, J., Cardoso, M. \& Díez, L. (2019). Desindustrialización prematura en España. BBVA Research, Observatorio Económico, 5 de marzo.

Blázquez, L., Díaz-Mora, C. \& González-Díaz, B. (2017). La servitización de las cadenas globales de valor: una aproximación a partir del análisis de redes sociales. Cuadernos Económicos de ICE, 94, 87-114. https://doi.org/10.32796/cice.2017.94.6554

Boix-Domenech, R. (2008, May 27-29). Industrial districts, innovation and l-district effect: Territory or industrial specialization? [Conference]. Regional Studies Association International Conference, Praga.

Boix-Domenech, R. \& Trullén, J. (2011). La relevancia empírica de los distritos industriales marshallianos y los sistemas productivos locales manufactureros de gran empresa en España. Investigaciones Regionales, 19, 75-96.

Chang, H. J., Andreoni, A. \& Kuan, M. L. (2013). International industrial policy experiences and the lessons for the UK. Centre for Business Research, University Of Cambridge, Working Paper No. 450.

Consejo de la Unión Europea (2019, May). An EU Industrial Policy Strategy: a Vision for 2030. Council conclusions.
Corrado, C., Haskel, J., Jona-Lasinio, C. \& lommi, M. (2016). Intangible investment in the EU and US before and since the Great Recession and its contribution to productivity growth. European Investment Bank (EIB), Working Papers No. 8.

Delgado, M. \& Mills, K. G. (2018). A New Categorization of the US Economy: The Role of Supply Chain Industries in Innovation and Economic Performance. Harvard Business School, Working Paper No. 18-068.

Donoso, V. \& Martín, V. (2017). Complejidad económica y densidad productiva como fuentes de competitividad. Estudios de Economía Aplicada, 35(1), 85-110.

Gandoy, R., Díaz-Mora, C., Córcoles, D. \& González-Díaz, B. (2016). Inserción en las cadenas de valor internacionales. En R. Myro (dir.), Una nueva política industrial para España, cap. 9 (pp. 133-151). Consejo Económico y Social España.

Hausmann, R. \& Klinger, B. (2007). The structure of product space and the evolution of comparative advantage. CID, Working Paper No. 146.

HM Government (2018). The economic value of data: discussion paper. HM Treasury. https:/lassets.publishing.service.gov. uk/government/uploads/system/uploads/attachment data/ file/731349/20180730_HMT_Discussion_Paper_-_The_Economic_Value_of_Data.pdf

Krugman, P. R. (1992). Motivos y dificultades en la política industrial. En C. Martín (ed.), Política industrial: teoría y práctica (pp. 21-46). Colegio de Economistas de Madrid.

Maloney, W. F. \& Nayyar, G. (2017). Industrial Policy, Information, and Government Capacity. World Bank, Policy Research Working Paper No. 8056.

Marin, D. (2020, May). Europe needs a DARPA. Project Syndicat, opinion.

Mazzucato, M. (2014). El Estado emprendedor. Mitos del sector público frente al privado. RBA.

Minondo, A. (2021). Impact of COVID-19 on the trade of goods and services in Spain. Applied Economic Analysis. http://dx. doi.org/10.1108/AEA-11-2020-0156

Moral, M. J. (2020). Dificultades en el sector de automoción español: incertidumbre sobre el modelo de movilidad y colapso de las exportaciones por la pandemia. Cuadernos de Información Económica, 277, 33-40.

Moreno García-Cano, L. O. \& Fernández de Bobadilla, A. (2019). El futuro de la relación España-Marruecos: hacia una cadena de valor euromediterránea. Boletín Económico de ICE, 3115, 37-47. https://doi.org/10.32796/bice.2019.3115.6903

Myro, R. (1994). La política industrial activa. Revista de Economía Aplicada, 2(6), 171-182.

Myro, R. (director) (2016). Una nueva política industrial para España. Consejo Económico y Social España.

Myro, R. (2018). La apuesta por la industria y la política industrial. En E. Huerta \& M. a J. Moral (eds.), Innovación y competitividad: desafíos para la industria española, cap. 3 (pp. 117-139). FUNCAS. 
Myro, R. (2019). A policy for a new industrial revolution. Journal of Industrial and Business Economics, 46(3), 403-414.

OCDE, Organización para la Cooperación y el Desarrollo Económico (2015). Data-driven Innovation: Big Data for Growth and Well-being.

Paniagua, J. (2020, 22 de abril). La COVID-19 y la seguridad de suministro de equipos sanitarios esenciales. Funcasblog.

Prades, E. \& Tello, P. (2020). Heterogeneidad en el impacto económico del COVID-19 entre regiones y países del área del euro. Boletín Económico del Banco de España n. ${ }^{\circ} 2$.

Rodríguez-Clare, A. (2004). Clusters and comparative advantage: Implications for industrial policy. Journal of Development Economics, 82(1), 43-57.
Rodríguez, D. (2021). Industria y transición energética. Información Comercial española (ICE), Revista de Economía, 919, 83-103. https://doi.org/10.32796/ice.2021.919.7174

Rodrik, D. (2004). Industrial policy for the twenty-first century. In D. Rodrik, One Economics, Many Recipes: Globalization, Institutions, and Economic Growth (pp. 99-151). Princeton University Press.

Scheifler, M. (2020, 26 de noviembre). Objetivo: Elegir España. Blog de Slfdi.

Scholtes Ruiz, R. (2019). Impacto del vehículo eléctrico en la industria española: disrupción económica en ciernes. Economía Industrial, 411, 113-122.

Yergin, D. (2020). The New Map: Energy, Climate, and the Clash of Nations. Allen Lane. 